Trakya Üniversitesi

Eğitim Fakültesi Dergisi

XV. Uluslararası Katılımlı Sınıf Öğretmenliği

Eğitimi Sempozyumu (11-14 Mayıs 2016)

USOS 2016 Özel Sayısı, 47-67

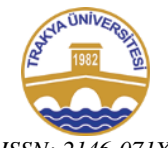

ISSN: 2146-071X
Trakya University

Journal of Education Faculty

XV. International Primary Teacher Education

Symposium (11-14 May 2016)

IPTES 2016 Special Issue, 47-67

Doi: $10.24315 /$ trkefd. 364025

\title{
Sınıf Öğretmeni Adaylarının Matematiksel Okuryazarlık Kavramına İlişkin Metaforik Algıları ${ }^{1}$
}

\section{Prospective Primary Teachers' Methaphorical Perceptions about the Concept of Mathematical Literacy}

\section{Pusat PILTEN², Ramazan DIVRİK ${ }^{3}$, Gülhiz PILTEN ${ }^{4}$, Abdullah EBRET $^{5}$}

\begin{abstract}
Öz: $\mathrm{Bu}$ araştırmanın amacı, sınıf öğretmeni adaylarının "matematiksel okuryazarlık" kavramına yönelik algılarını metaforlar yoluyla ortaya koymaktır. Olgubilim modelinde gerçekleştirilen bu araştırmanın çalışma grubunu Türkiye' de eğitim-öğretim faaliyeti sürdürmekte olan 6 devlet üniversitesinin Sınıf Eğitimi Anabilim Dallarında öğrenim görmekte olan 1525 öğrenci oluşturmaktadır. Araştırma verileri "Matematiksel okuryazarlık ..... gibidir, çünkü......" formunun doldurulmasıyla elde edilmiştir. Verilerin analizinde metafor analiz basamakları ve frekans analizi kullanılmıştır. Çalışma bulgularına göre sınıf öğretmeni adayları toplam 94 metafor üretmiş ve bu metaforlar 11 kategori altında toplanmıștır. İfade edilen metaforlar en fazla günlük hayat faaliyeti, bir araç-alet kullanma becerisi, mutfak faaliyeti, zihinsel beceri, işlevsel bir araç gibi kategoriler altında toplanmıştır. Sınıf öğretmeni adayları tarafindan ortaya konulan metaforlardan en fazla tekrar edilenler; yemek hazırlama, bilgisayar kullanma, alışveriş yapma, araba kullanma, problem çözme, dünya, telefon kullanma, yapboz, orman, gelecek, uzay şeklinde sıralanmıştır. En fazla tekrar edilen metaforlar değerlendirildiğinde, bunların pek çoğunun üst düzey düşünme becerilerini (analiz, sentez, değerlendirme vb.) gerektirdiği görülmektedir.
\end{abstract}

Anahtar sözcükler: Matematiksel okuryazarlık, metafor, sinıf ögretmeni adayl.

\footnotetext{
1 Bu çalışma 11-14 Mayıs 2016 tarihinde Muğla Sitkı Koçman Üniversitesi tarafindan düzenlenen XV. Uluslararası Sinıf Öğretmenliği Eğitimi Sempozyumu'nda sözlü bildiri olarak sunulmuştur.

2 Yrd. Doç. Dr., Necmettin Erbakan Üniversitesi, e-posta: ppilten@hotmail.com

3 Doktora Öğrencisi, Necmettin Erbakan Üniversitesi, e-posta: rdivrik42@gmail.com

4 Yrd. Doç. Dr., Necmettin Erbakan Üniversitesi, e-posta: gulhizp@yahoo.com.tr

5 Yüksek Lisans Öğrencisi, Necmettin Erbakan Üniversitesi e-posta: abdullahebret@hotmail.com
} 


\begin{abstract}
The purpose of this research is to reveal prospective primary teachers' perceptions about the concept of "mathematical literacy" by means of metaphors. The working group of this research, executed with phenomenology method, consists of 1525 students studying in the department of Primary Education of 6 public university, maintaining educational activities, in Turkey. Research data was collected by completing the following form: "Mathematical literacy is like ..., because ....". Metaphor analysis steps and frequency analysis were used when analyzing the data. According to research evidences, class teacher candidates produced 94 metaphors and these metaphors were grouped under 11 categories. Stated metaphors were mostly grouped under the categories such as daily life activity, the ability to use equipment, kitchen activity, cognitive ability and a functional instrument. The most frequently repeated metaphors by class teacher candidates were arranged as; preparing a meal, using a computer, doing shopping, driving a car, solving a problem, earth, using phone, jigsaw, forest, future and space. When the most frequently repeated metaphors were evaluated, it was seen that they required high level thinking skills (analysis, synthesis, evaluation).
\end{abstract}

Keywords: Mathematical literacy, metaphor, prospective primary teacher.

\title{
1. GíRiş
}

Matematiksel okuryazalık kavramının son yıllarda özellikle uluslararası sinavlarda sıklıkla vurgulandığı görülmektedir (OECD, 2006; TIMMS, 2003). Bunlardan Uluslararası Öğrenci Değerlendirme Programı (PISA) kavramı, bireylerin yapılandırıcı, ilgili ve yansıtıcı vatandaşlar olma yolunda, iyi temellendirilmiş yargılarda bulunma ve kendi hayatlarında ihtiyaç duyacakları matematiğin rolünü anlama ve tanımlama kapasiteleri olarak tanımlamaktadır (OECD, 2006).

Kavramı açıklayıcı nitelikteki diğer bir tanım da Alberta Matematik Öğretmenleri Derneği (MCATA, 2000) tarafından bireyin hayatında karşılaştı̆̆ sayısal becerileri gerektiren durumlara etkili bir katılım sağlamak için ihtiyaç duyduğu beceri, bilgi, inanç, eğilim, zihinsel alışkanlıklar, iletişim ve problem çözme becerilerinin tamamı şeklinde yapılmaktadır.

Yine aynı kurumun, kavramın yapısını açıklayıcı nitelikteki bir başka tanımı ise şu şekildedir; matematiksel okuryazarlık; matematiği dünya ile ilişkilendirmek, farklı durumlarda uygun şekilde kullanmak, matematik dilinin zenginliğini kullanarak anlatım yapmak, matematiksel düşünceleri sentezlemek, analiz etmek ve değerlendirmek, matematiğin yararını takdir etmek, matematiği anlamak ve matematiksel olarak ne öğrenildiğinin farkında olmaktır (MCATA, 2000).

Yukarıdaki tanımlar incelendiğinde, matematiksel okuryazarlık kavramının aşağıdaki unsurları içerdiği görülmektedir (Aksu, Demir ve Sümer, 1998; MCATA, 2000, Özgen ve Bindak, 2011; Tekin ve Tekin, 2004):

- Matematiğin gerçek hayatla bütünleştirilebilmesi, 
- Matematiksel ilişkileri toplumsal ve bilimsel olaylar içerisinde görülebilmesi, yorumlanabilmesi ve kullanılabilmesi,

- Matematiğin çeşitli konu alanı içeriklerinde (sayılar, ölçme, geometri vb.) doğru biçimde kullanılabilmesi,

- Genel matematiksel yeterliliklerin (problem çözme, akıl yürütme vb.) kullanılabilmesi,

- Matematik dilini kullanarak iletişim kurulabilmesi,

- Diğerlerinin matematiksel düşüncelerine ilişkin analiz, sentez ve değerlendirmeler yapılabilmesi,

- Matematiğin estetik ve faydalı olduğuna dair değerlendirmeler yapabilmesi,

- Matematiksel olarak neler öğrenebileceğinin farkında olunması,

Yukarıda da ifade edildiği gibi matematiksel okuryazarlık, literatürde kapsamı detaylı biçimde ortaya konulmuş ve son dönemlerde sıklıkla vurgulanan bir kavram olarak karşımıza çıkmaktadır. Ulusal Matematik Öğretmenleri Derneği (NCTM, 2000), matematiksel okuryazarlık kavramını matematik eğitiminin temel amaçları arasında sıralamaktadır. Aynı şekilde PISA, kavramın önemini vurgulamakta, matematiksel okuryazarlığı geliştirme faaliyetlerinde yalnızca öğretim programı ile sınırlandırılma yapılamayacağından, fonksiyonel olarak günlük hayatta karşılaşılan durumlarda öğrencilerin problem çözme, analiz, akıl yürütme, iletişim becerilerinin, birçok farklı bağlamda karşılaşabilecekleri matematiksel problemlere çözümler hazırlama kapasitelerinin geliştirilmesinin amaçlanmasının gerekliliğinden bahsetmektedir (OECD, 2006). Bunlara ek olarak Milli Eğitim Bakanlı̆̆ı (MEB, 2005) tarafindan, matematik öğretim programlarında ortaya konulan yaklaşım, öğretim süreci ve becerilerin de matematik okuryazarlığı kavramıyla ilişkili olduğu görülmektedir. Ancak PISA 2006 ve PISA 2009 değerlendirme raporları incelendiğinde, PISA 2006 matematik okuryazarlığı ölçeğinde öğrencilerimizin \%76,4' ünün uzmanlar tarafindan temel yeterlik düzeyi olarak kabul edilen ikinci düzeyi veya aşağısında bulunduğu, PISA $2009^{\prime}$ da ise \%42,2' sinin ikinci düzeyin altında olduğu görülmektedir (EARGED, 2010). Bu sonuçlar, Türkiye' nin matematik okuryazarlığı ortalama puanının, OECD ülkeleri ilgili puanlarının ortalamasının altında olması bulgusuyla birlikte değerlendirildiğinde, öğrencilerimizin yeterli düzeyde matematiksel okuryazarlık becerisine sahip bireyler olmadıkları şeklinde yorumlanabilir.

$\mathrm{Bu}$ anlamda yukarıda literatüre dayalı biçimde kapsamı ve önemi ortaya konulmaya çalışılan matematiksel okuryazarlık becerisinin öğrencilere kazandırılmasına ilişkin çalışmaların bütün yönleriyle ve detaylı biçimde araştırılması önemli görülmektedir. Bu araştırmada Türkiye' de eğitim sisteminin uygulayıcıları olarak nitelendirilebilecek öğretmenlerin yetiştirildiği kurumlar olarak tanımlanan eğitim fakültelerinin, Sınıf Eğitimi A.D.' nda öğrenim görmekte olan aday öğretmenlerin kavrama ilişkin algılarının tespit edilmesine çalışılmıştır. 
$\mathrm{Bu}$ amaçla araştırmanın problem cümlesi "Sınıf öğretmeni adaylarının matematiksel okuryazarlık kavramına ilişkin metaforik algıları nedir?" ş̧eklinde oluşturulmuştur.

\section{YÖNTEM}

\subsection{Araştırmanın Deseni}

Araştırma, nitel araştırma desenlerinden biri olan ve bize tümüyle yabancı olmayan aynı zamanda da tam anlamını kavrayamadığımız belli bir olguya ilişkin bireysel algıların veya perspektiflerin ortaya çıkarılması ve yorumlanması amaçlanan, olguların araştırılmasında en etkili desen olarak tanımlanan "olgu bilim” deseni kullanılarak yürütülmüştür (Yıldırım ve Şimşek, 2005). Olgu bilim deseninin, diğer nitel araştırma desenlerine oranla araştırmacıya, yargıları, önyargıları, varsayımları daha iyi ortaya koyma imkânı vermesinin, öğretmen adaylarının söz konusu kavrama ilişkin algılarının daha derinlemesine anlaşılmasını sağlayacağı düşünülmüştür (Finlay, 2008). Bu araştırmada odaklanılan olgu yukarıda da bahsedildiği gibi öğretmenlerin matematiksel okuryazarlık kavramına ilişkin algılarıdır.

\section{2. Çalışma Grubu}

Araştırmanın çalışma grubunu, Türkiye' de eğitim-öğretim faaliyetlerini sürdürmekte olan 6 devlet üniversitesinin, Sınıf Eğitimi Anabilim Dallarında, 2015-2016 öğretim yılı güz döneminde öğrenim görmekte olan 1525 öğrenci oluşturmaktadır.

Bu çalışmada nitel araştırma geleneği içinde yer alan amaçlı örnekleme tekniklerinden "kolay ulaşılabilir" örnekleme tekniği kullanılmıştır. Literatürde kolay ulaşılabilir durum örneklemesi yöntemi araştırmalara hız ve pratiklik kazandırması özelliği ile tanımlanmaktadır. Ayrıca bu tür örneklemeler genellikle, kolay ulaşılabilen örneklemler göreli olarak daha az maliyetlidirler ve gerçekte nitel araştırmalarda maliyet ve ulaşılabilirlik, örneklem kararında dikkate alınması gereken etkenlerden biri olarak tanımlanmaktadır (Yıldırım ve Şimşek, 2005). Bu nedenlerle, araştırmacılar, mümkün olduğunca fazla sayıda ve farklı üniversitelerde öğrenim görmekte olan sınıf öğretmeni adaylarının algılarını belirleyebilmek için, kolay ulaşılabilir bir grubu araştırmaya dâhil etmeyi dolayısıyla kolay ulaşılabilir durum örneklemesini kullanmayı tercih etmişlerdir. Araştırmanın çalışma grubunda yer alan öğrencilerin bazı özellikleri Tablo 1'de sunulmuştur. 
Tablo 1. Çalışma grubunda yer alan öğrencilerin bazı özellikleri

\begin{tabular}{|c|c|c|c|c|c|c|c|c|c|c|c|c|c|}
\hline \multirow[t]{3}{*}{ Üniversite } & \multicolumn{8}{|c|}{ Sinıf Seviyesi } & \multicolumn{4}{|c|}{ Cinsiyet } & \multirow[t]{3}{*}{ TOPLAM } \\
\hline & \multicolumn{2}{|c|}{1} & \multicolumn{2}{|c|}{2} & \multicolumn{2}{|c|}{3} & \multicolumn{2}{|c|}{4} & \multicolumn{2}{|c|}{ Kadın } & \multicolumn{2}{|c|}{ Erkek } & \\
\hline & f & $\%$ & $\mathbf{f}$ & $\%$ & f & $\%$ & f & $\%$ & $\mathbf{f}$ & $\%$ & f & $\%$ & \\
\hline $\mathbf{A}$ & 74 & 4,85 & 85 & 5,57 & 132 & 8,65 & 93 & 6,10 & 289 & 18,95 & 95 & 6,22 & 384 \\
\hline $\mathbf{B}$ & 50 & 3,27 & 54 & 3,54 & 49 & 3,21 & 48 & 3,14 & 135 & 8,86 & 66 & 4,32 & 201 \\
\hline $\mathbf{C}$ & 47 & 3,08 & 46 & 3,01 & 40 & 2,62 & 44 & 2,88 & 118 & 7,74 & 59 & 3,88 & 177 \\
\hline D & 54 & 3,54 & 56 & 3,67 & 53 & 3,47 & 58 & 3,80 & 143 & 9,37 & 78 & 5,12 & 221 \\
\hline $\mathbf{E}$ & 58 & 3,80 & 72 & 4,72 & 64 & 4,20 & 66 & 4,32 & 162 & 10,62 & 98 & 6,42 & 260 \\
\hline $\mathbf{F}$ & 65 & 4,26 & 69 & 4,52 & 70 & 4,60 & 78 & 5,11 & 183 & 12,00 & 99 & 6,50 & 282 \\
\hline Toplam & 348 & 22,82 & 382 & 25,05 & 408 & 26,75 & 387 & 25,38 & 1030 & 67,54 & 495 & 32,46 & 1525 \\
\hline
\end{tabular}


Tablo 1 incelendiğinde çalışmaya $495(\% 32,46)$ erkek ve $1030(\% 67,54)$ kadın olmak üzere toplam 1525 sınıf öğretmeni adayının katıldığ görülmektedir. Cinsiyete göre dağılımın, Sınıf Eğitimi Anabilim Dalı öğrencilerinin genel profilini yansıttığı düşünülmektedir. Ayrıca sınıf öğretmeni adaylarının sınıflara göre dağılımının neredeyse denk olduğu ifade edilebilir.

\subsection{Verilerin Toplanması}

Araştırmada hedeflenen, bir kavram, olgu veya olayın başka bir kavram, olgu veya olaya benzetilerek açıklanmasını içeren metaforların kullanılarak, sınıf öğretmeni adaylarının, matematiksel okuryazarlık kavramına ilişkin algılarının betimlenmesidir (Oxford et al., 1998). Metaforlar insanın doğayı ve çevresini anlamasının, anlamsız gibi görünen nesnel gerçeklikten belirli yorumlar yoluyla anlamlar çıkarmasının, yaşantı ve deneyime anlam kazandırmanın araçları olarak "bilmeye" de olanak sağlamaktadır (Yıldırım ve Şimşek, 2005).

Belirtilen hedef doğrultusunda öncelikle araştırmanın çalışma grubunda yer alan öğrencilere metafor tekniği hakkında bilgi verilmiştir. Daha sonra katılımcıların matematiksel okuryazarlık kavramına ilişkin sahip oldukları metaforları ortaya çıkarmak amacıyla onların her birinden "Matematiksel okuryazarlık...... gibidir, çünkü ......" ifadesini tamamlamaları istenmiştir. Aday öğretmenlerden bu ifadeyi kullanarak ve sadece tek bir metafor üzerinde yoğunlaşarak düşüncelerini dile getirmeleri istenmiştir. Aday öğretmenlere kavramla ilgili metaforlar oluşturmaları için 30 dakika süre verilmiştir. Oluşturulan bu metaforlar araştırmanın temel veri kaynağını oluşturmaktadır.

\subsection{Verilerin Analizi}

Araştırma verilerinin analiz edilmesinde, Saban (2008) tarafından ortaya konulan metafor analiz sürecinin basamakları izlenmiştir. Ayrıca aynı metaforları kullanan öğretmen adaylarının ortaya konulması için frekans analizi de kullanılmıştır. Tavşancıl ve Aslan (2001), frekans analizinin birimlerin nicel olarak görülme sıklığını ortaya koyduğunu; frekans analizi yardımıyla sıklığa dayalı bir sınıflama yapılabileceğini, öğelerin önem ve etki derecelerine ilişkin yorumda bulunulabileceğini belirtmektedirler. Verilerin analizi kapsamında gerçekleştirilen metafor analiz basamakları aşağıda açıklanmıştır.

Kodlama ve Ayıklama Aşaması: Katılımcılar tarafindan üretilen metaforların alfabetik sıraya göre geçici bir listesi yapılmıştır. Bu amaç doğrultusunda katılımcıların yazılarında belli bir metaforu net bir şekilde dile getirip getirmediğine bakılmıştır. Bu aşamada basitçe her katılımcının sunduğu metafor kodlanmıştır. Bu aşamada, ayrıca, herhangi bir metafor imgesini içermeyen kâğıtlar ile boş bırakılan kağıtlar $(n=36)$ ayıklanmıştır. Bazı katılımcılar, örneğin, bir metafor imgesini sunmak yerine, genel olarak, matematikle ilgili kişisel düşüncelerini paylaşmıştır. Yine, bazı katılımcılar belli bir metafor imgesini dile getirdiği halde, söz konusu metafora ilişkin herhangi bir gerekçe (ya da mantıksal dayanak) sunmamıştır. Bazı katılımcılar da birden fazla kategoriye ait özellikleri içeren metaforlar üretmiştir. Bütün bu gerekçelere bağlı olarak 36 adet kâğıt elenerek araştırma kapsamı dışında bırakılmıştır. 
Örnek metafor imgesi derleme aşaması: Katılımcıların zayıf yapılı metafor imgelerini içeren kağıtların ayıklanmasından sonra, toplam 94 adet geçerli metafor elde edilmiştir. Bu aşamada, bu metaforlar tekrar alfabetik sıraya göre dizilmiş ve ham veriler ikinci kez gözden geçirilerek her metaforu temsil eden katılımcı kompozisyonlarından birer "örnek metafor ifadesi” seçilmiştir. Böylece, 94 metaforun her biri için onu en iyi temsil ettiği varsayılan katılımcı metafor imgelerinin derlenmesiyle birlikte bir "örnek metafor listesi”" oluşturulmuştur. $\mathrm{Bu}$ liste, iki temel amaca yönelik olarak derlenmiştir: (a) metaforların belli bir kategori altında toplanmasında bir başvuru kaynağı olarak kullanmak ve (b) bu araştırmanın veri analiz sürecini ve yorumlarını geçerli kılmak.

Kategori gelişstirme aşaması: $\mathrm{Bu}$ aşamada, temel olarak katılımcılar tarafindan üretilen metafor imgeleri matematiksel okuryazarlık olgusuna ilişkin sahip oldukları ortak özellikler bakımından irdelenmiştir. Bu işlem esnasında özellikle 94 metafor hakkında oluşturulan "örnek metafor listesi” baz alınarak her metafor imgesinin matematiksel okuryazarlık olgusunu nasıl kavramsallaştırdığına bakılmıştır. Bu amaç için, katılımcılar tarafından üretilen her metafor imgesi (1) metaforun konusu, (2) metaforun kaynağ 1 ve (3) metaforun konusu ile kaynağı arasındaki ilişki bakımlarından analiz edilmiştir. Daha sonra her metafor imgesi matematiksel okuryazarlığa ilişkin sahip olduğu perspektif bakımından belli bir tema ile ilişkilendirilerek (örneğin, "zihinsel beceri ve işlevsel bir araç olarak matematiksel okuryazarlık", vb.) toplam 11 farklı kavramsal kategori oluşturulmuştur.

Geçerlik ve güvenirliği sağlama aşamast: Toplanan verilerin ayrıntılı olarak rapor edilmesi ve araştırmacının sonuçlara nasıl ulaştığını açıklaması nitel bir araştırmada geçerliğin önemli ölçütleri arasında yer almaktadır (Yıldırım ve Şimşek, 2005). Bu araştırmaya özgü olarak, araştırma sonuçlarının geçerliğini sağlamak amacıyla iki önemli işlem gerçekleştirilmiştir: (1) Veri analiz süreci (özellikle de 11 kavramsal kategoriye nasıl ulaşıldığı) detaylı bir şekilde açıklanmıştır. (2) Araştırmada elde edilen 94 metaforun her biri için onu en iyi temsil ettiği varsayılan bir örnek metafor imgesi derlenmiş ve bu metafor imgelerinin tümüne bulgular kısmında yer verilmiştir. Araştırmanın güvenirliğini sağlamak için, araştırmada ulaşılan 11 kavramsal kategori altında verilen metafor imgelerinin söz konusu bir kavramsal kategoriyi temsil edip etmediğini teyit etmek amaciyla uzman görüşüne başvurulmuştur.

Nicel veri analizi için verileri SPSS paket programına aktarma aşaması: Toplam 94 adet metaforun belirlenmesinden ve bu metaforların oluşturduğu 11 adet kavramsal kategorinin geliştirilmesinden sonra, bütün veriler SPSS paket programına aktarılıp 94 metaforu ve 11 kavramsal kategoriyi temsil eden katılımcı sayısı (f) ve yüzdesi (\%) hesaplanmıştır.

\section{BULGULAR}

Araştırmada elde edilen verilerin analizi sonucunda öğretmen adaylarının matematiksel okuryazarlık kavramına ilişkin oluşturdukları metaforların, araştırmacılar tarafından yerleştirildikleri kategoriler Tablo $2^{\prime}$ de sunulmuştur. 
Tablo 2. Öğretmen adayları tarafından oluşturulan metaforların ait oldukları kategoriler

\begin{tabular}{lll}
\hline Metafor & f & \% \\
\hline Bir Araç-Alet Kullanma Becerisi & 348 & 23,37 \\
Günlük Hayat Faaliyeti & 443 & 29,75 \\
Mutfak Faaliyeti & 217 & 14,57 \\
Zihinsel Beceri & 212 & 14,23 \\
Karmaşı Bir Yapı & 38 & 2,55 \\
Parça-Bütün İlişkisi & 51 & 3,42 \\
El Becerisi & 19 & 1,27 \\
Uyum ve Düzen Gerektiren Yapılar & 132 & 8,86 \\
İşlevsel Bir Araç & 18 & 1,20 \\
Bir Kurum & 5 & 0,30 \\
Bir Kişi & 6 & 0,36 \\
\hline TOPLAM & $\mathbf{1 4 8 9}$ & $\mathbf{1 0 0}$ \\
\hline
\end{tabular}

Tablo 2 incelendiğinde sınıf öğretmeni adayları tarafından üretilen 1489 metaforun toplam 11 kategori altında toplandığ 1 görülmektedir. Bu kategorilerden “'Günlük Hayat Faaliyeti' ' kategorisi \% 29,75 (443) ile en yüksek, “Bir Kurum”, kategorisi \% 0,30 (5) ile en az metafora sahiptir. Tablo 2' de ortaya konulan her bir kategori ve bunlara ilişkin metafor alt kategorileri aşağıda ele alınmıştır.

Matematiksel okuryazarlığ bir araç ya da alet kullanma becerisi olarak tanımlayan öğretmen adaylarının oluşturdukları metafor alt kategorileri Tablo 3' de sunulmuştur.

Tablo 3. Bir araç-alet kullanma becerisi olarak matematiksel okuryazarlık

\begin{tabular}{lll}
\hline Metafor & $\mathbf{f}$ & $\mathbf{\%}$ \\
\hline Araba kullanma & 101 & 6,78 \\
Uçak kullanma & 17 & 1,14 \\
Telefon kullanma & 41 & 2,75 \\
Ney üfleme & 4 & 0,26 \\
Gitar çalma & 2 & 0,13 \\
Bağlama çalma & 3 & 0,20 \\
El feneri kullanma & 1 & 0,06 \\
Arama motoru kullanma & 7 & 0,47 \\
Bilgisayar kullanma & 128 & 8,60 \\
Bankamatik kullanma & 38 & 2,55 \\
Dürbün kullanma & 4 & 0,26 \\
Teleskop kullanma & 2 & 0,13 \\
\hline TOPLAM & $\mathbf{3 4 8}$ & $\mathbf{2 3 , 3 7}$ \\
\hline
\end{tabular}

Tablo 3 incelendiğinde, araştırmanın çalışma grubunda yer alan öğrencilerden 348' inin $(\% 23,37)$ matematiksel okuryazarlığa ilişkin metaforlarının, "Bir Araç-Alet Kullanma Becerisi" kategorisinde toplandığı belirlenmiştir.

Yine Tablo 3' de bunlardan "Bilgisayar Kullanma" (\%8,60), "Araba Kullanma" (\%6,78), "Telefon Kullanma" (\%2,75), "Bankamatik Kullanma" $(\% 2,55)$ ve "Uçak Kullanma" $(\% 1,14)$ baskın metaforlar olarak 
değerlendirilmiştir. $\mathrm{Bu}$ değerlendirmeleri destekleyici nitelikte bazı aday öğretmen görüşleri şu şekildedir:

"Matematiksel okuryazarlık bilgisayar kullanma gibidir çünkü bilgisayarlar da matematik gibidir. Kullanmayı bilmeyen bu dönemde hiç bir şey yapamaz, okulunu bitiremez, iş hayatında zorlanır. Matematiği kullanabilme de bilgisayar kullanımı gibi karmaşık ve zordur."

"Matematiksel okuryazarlık araba kullanma gibidir çünkü, araba kullanırken pek çok şeyi bilip bir arada yapabilmeniz gerekir, ayrıca yeni bir durumda ona uygun tepkiyi vermelisiniz. Hayatta matematik her alanda, dolayısıla her an yeni bir durum karşımıza çıkabiliyor. Bu yeni durumu anlayıp çözümlememiz gerekiyor."

"Matematiksel okuryazarlık telefon kullanma gibidir çünkü, akıllı telefonların pek çok özelliği var. Onu etkili kullanabilmek için bu ilişkili, ilişkisiz özelliklerin tamamını kullanabilmeyiz. Matematikte de aynı, matematiğin pek çok özelliğini bilip, uygulayabilmeliyiz. Tabii matematiği anlama ve kendini ifade etme de benziyor."

Matematiksel okuryazarlığı bir günlük hayat faaliyeti olarak tanımlayan öğretmen adaylarının oluşturdukları metafor alt kategorileri Tablo 4' de sunulmuştur.

Tablo 4. Günlük hayat faaliyeti olarak matematiksel okuryazarlık

\begin{tabular}{lll}
\hline Metafor & f & $\mathbf{\%}$ \\
\hline Yemek hazırlama & 217 & 14,57 \\
Alışveriş yapma & 128 & 8,60 \\
Bütçe planlama & 30 & 2,01 \\
Dolmuşa - otobüse binme & 13 & 0,87 \\
Gezi planlama & 5 & 0,33 \\
Fatura ödeme & 4 & 0,26 \\
Hediye alma & 17 & 1,14 \\
Valiz hazırlama & 2 & 0,13 \\
Çamaşır yıkama & 1 & 0,06 \\
Kitap okuma & 3 & 0,20 \\
Makyaj yapma & 9 & 0,60 \\
Dil öğrenme & 3 & 0,20 \\
Not hesaplama & 11 & 0,74 \\
\hline TOPLAM & $\mathbf{4 4 3}$ & $\mathbf{2 9 , 7 5}$ \\
\hline
\end{tabular}

Tablo 4 incelendiğinde, araştırmanın çalışma grubunda yer alan öğretmen adaylarından 443' nün $(\% 29,75)$ matematiksel okuryazarlığa ilişkin metaforlarının, "Günlük Hayat Faaliyeti” kategorisinde toplandığı görülmektedir.

Bunlardan "Yemek Hazırlama" (\%14,57), "Alışveriş Yapma" (\%8,60), "Bütçe Planlama" (\%2,01), "Hediye Alma" $(\% 1,14)$ ve "Dolmuşa-otobüse Binme" (\%0,87) baskın metaforlar olarak değerlendirilmiştir (Tablo 4). Bu değerlendirmeyi destekleyici nitelikte bazı aday öğretmen görüşleri şu şekildedir:

"Matematiksel okuryazarlık yemek hazırlama gibidir çünkü bütün insanlar her gün yemek yemek ve hazırlamak zorundalar, matematiği de hayatta her gün kullanmalıyı." 
"Matematiksel okuryazarlı alışveriş yapma gibidir çünkü her ikisinde de aynı işlemleri yaparız. Alışveriş yaparken ihtiyaçlarımıza ve bütçemize göre nelerden ne kadar alacağımızı hesaplarız. Bu matematiksel okuryazarlıktır."

"Matematiksel okuryazarlık aylık bütçemizi hesaplama gibidir çünkü, bütçe hazırlarken bir sürü faktörü birlikte değerlendirmemiz gerekir. Gelir, gider, özellikle giderleri öneme göre değerlendirmeliyiz. Bu bakımdan benzer."

Matematiksel okuryazarlığı bir mutfak faaliyeti olarak tanımlayan öğretmen adaylarının oluşturdukları metafor alt kategorileri Tablo 5' de sunulmuştur.

Tablo 5. Mutfak faaliyeti olarak matematiksel okuryazarlık

\begin{tabular}{lll}
\hline Metafor & f & \% \\
\hline Kek yapma & 42 & 2,82 \\
Pasta yapma & 37 & 2,48 \\
Brovni yapma & 11 & 0,74 \\
Börek yapma & 12 & 0,80 \\
Türlü yapma & 41 & 2,75 \\
Serpme kahvaltı & 28 & 1,88 \\
Milkshake & 7 & 0,47 \\
Pizza yapma & 39 & 2,62 \\
\hline TOPLAM & $\mathbf{2 1 7}$ & $\mathbf{1 4 , 5 7}$ \\
\hline
\end{tabular}

Tablo 5 incelendiğinde, araştırmanın çalışma grubunda yer alan öğrencilerden 217' sinin $(\% 14,57)$ matematiksel okuryazarlığa ilişkin metaforlarının, "Mutfak Faaliyeti” kategorisinde toplandığ 1 görülmektedir.

Bunlardan "Kek Yapma” (\%2,82), "Türlü Yapma” (\%2,75), "Pizza Yapma" (\%2,62), "Pasta Yapma" $(\% 2,48)$ ve "Serpme Kahvaltı" $(\% 1,88)$ baskın metaforlar olarak değerlendirilmiştir (Tablo 5). Bu değerlendirmeyi destekleyici bazı aday öğretmen görüşleri şu şekildedir:

"Matematiksel okuryazarlı kek yapma gibidir çünkü kek yaparken un, süt, yumurta, neli kek yapacaksanız o malzeme bir araya getirilir. Ama herkes aynı keki yapamaz, bu malzemenin oranları kişiye göre değişir ve sonuçta ortaya çıkan kekin tadı hep farklıdır. Matematiksel okuryazarlıkta matematikle ilgili pek çok bilgiye sahip olmak yeterli değil. Bu bilgileri bir araya getirerek yorum yapabilmek önemli."

"Matematiksel okuryazarlı türlü yapma gibidir çünkü, türlü bir sürü sebze ile yapılır ama hangi sebzeleri kullanacă̆ınızı da bilmelisiniz, matematiksel okur yazar olabilmek için de, toplama, çıkarma, çarpma, bölme bilmelisiniz, daha önemlisi ne zaman hangisini kullanacă̆ınızı bilmelisiniz."

"Matematiksel okuryazarlı pasta yapma gibidir çünkü, pasta malzemelerini seçme ve bir araya getirme ne kadar zorsa, matematiği anlamak da o kadar zordur."

Matematiksel okuryazarlığı bir zihinsel beceri olarak tanımlayan öğretmen adaylarının oluşturdukları metafor alt kategorileri Tablo 6' da sunulmuştur. 
Tablo 6. Zihinsel beceri olarak matematiksel okuryazarlık

\begin{tabular}{lll}
\hline Metafor & f & $\mathbf{\%}$ \\
\hline Anlama & 11 & 0,74 \\
Akıl yürütme & 42 & 2,82 \\
Problem çözme & 55 & 3,69 \\
İlişkilendirme & 14 & 0,94 \\
Mantık & 3 & 0,20 \\
Modelleme & 3 & 0,20 \\
Soyut düşünme & 12 & 0,80 \\
Analiz & 17 & 1,14 \\
Sentez & 10 & 0,67 \\
Değerlendirme & 19 & 1,28 \\
Gruplama & 3 & 0,20 \\
Eşleştirme & 5 & 0,33 \\
Sayma & 2 & 0,13 \\
Aritmetik & 16 & 1,07 \\
\hline TOPLAM & $\mathbf{2 1 2}$ & $\mathbf{1 4 , 2 3}$ \\
\hline
\end{tabular}

Tablo 6 incelendiğinde, araştırmanın çalışma grubunda yer alan öğrencilerden 212' $\operatorname{sinin}(\% 14,23)$ matematiksel okuryazarlı̆̆a ilişkin metaforlarının, "Zihinsel Beceri” kategorisinde toplandığı görülmektedir.

Bunlardan "Problem Çözme" (\%3,69), "Akıl Yürütme” (\%2,82), "Değerlendirme" (\%1,28), "Analiz" $(\% 1,14)$ ve "Aritmetik" (\%1,07) baskın metaforlar olarak değerlendirilmiştir (Tablo 6). Bu değerlendirmeyi destekleyici nitelikte bazı aday öğretmen görüşleri şu şekildedir:

"Matematiksel okuryazarlı problem çözme gibidir çünkü problem çözmede de problemi okumamız, verilen istenenleri anlamamız buna göre de nasıl çözeceğimizi planlamamı gerekli. Matematiksel okuryazarlıkta da durum bu, hayatta fark etmeden bile olsa karşılaştığımız problemin çözümünde kullandığımız çözüm yöntemi matematiğe dayanır. Örneğin, bir yere geç kaldı̆̆ımızda en hızlı ulaşabilmek için tüm faktörlerin en uygununu seçmek zorunluluğu. Mesafeyi düşünmeliyiz, trafiği düşünmeliyiz, araba varsa park sorununu düşünmeliyiz, oraya en yakın yere park etmeli daha bir sürü şeyi düşünmeliyiz. Ve durumu anladiktan sonra bir karar vermeliyiz."

"Matematiksel okuryazarlık akıl yürütme gibidir çünkü nasıl bir bulmaca çözerken birçok ipucundan ve bildiklerimizden yola çıkarak bir şey bulmaya çalışıyoruz, bir anlamda akıl yürütüyoruz, matematiksel okuryazarlıkta böyle düşününce akll yürütme gibi."

"Matematiksel okuryazarlı değerlendirme gibidir çünkü değerlendirmenin tanımı neydi, ölçme sonuçlarını bir ölçütle karşılaştırarak yargıda bulunma. matematiksel okuryazarlıkta da aynı, duyu organlarımızla aldığımız her şeyi bildiğimiz matematik bilgilerini ölçüt olarak kullanarak yargillyoruz, değerlendirme yapıyoruz."

Matematiksel okuryazarlığı karmaşık bir yapı olarak tanımlayan öğretmen adaylarının oluşturdukları metafor alt kategorileri Tablo 7' de sunulmuştur. 
Tablo 7. Karmaşık bir yapı olarak matematiksel okuryazarlık

\begin{tabular}{lll}
\hline Metafor & f & $\mathbf{\%}$ \\
\hline Gelecek & 16 & 1,07 \\
Sinavlar & 9 & 0,60 \\
Bilmediğin bir şehir & 1 & 0,06 \\
Büyük bir bina & 1 & 0,06 \\
Labirent & 3 & 0,20 \\
Zeka küpü & 7 & 0,47 \\
Kadın çantası & 1 & 0,06 \\
\hline TOPLAM & $\mathbf{3 8}$ & $\mathbf{2 , 5 5}$ \\
\hline
\end{tabular}

Tablo 7 incelendiğinde, araştırmanın çalışma grubunda yer alan öğrencilerden $38^{\prime}$ inin $(\% 2,55)$ matematiksel okuryazarlığa ilişkin metaforlarının, "Karmaşık Bir Yapı” kategorisinde toplandığı görülmektedir.

Bunlardan "Gelecek” (\%1,07), "Sinavlar” (\%0,60), "Zekâ Küpü” (\%0,47), "Labirent" $(\% 0,20)$ baskın metaforlar olarak değerlendirilmiştir (Tablo 7). Bu değerlendirmeyi destekleyici nitelikteki bazı aday öğretmen ifadeleri şu şekildedir:

"Matematiksel okuryazarlık bir üniversite ögrrencisinin geleceği gibidir çünkü mezun olabilecek miyim? Hangi dershaneye gideceğim? Kaç para? Kpss' den kaç alacă̆ım? Millet kaç alacak? Atanacak mıyım? Nereye? Ordan kurtulabilecek miyim? Evlenecek miyim? Ne zaman? Kiminle? Bütün bu karmaşa aynen matematiksel okuryazarlık için geçerlidir. Herhangi içinde matematik olan durumu anlamak, çözme ve bunu uygulamak."

"Matematiksel okuryazarlık sinavlar gibidir çünkü, aslında bir şeyler bilirsin ama bunlar karşıdakinin istediği gibi bir araya getirmek zordur. Çoğunlukla yanlış tercihle yanlış yöne gidersin ve zaylf alırsın."

"Matematiksel okuryazarlı zeka küpü gibidir çünkü, zeka küpü bozuk olduğunda son derece karmaşıktır. Çözebilmek için belki on hareket sonrasını düşünmen gerekir, bir de belli bir tecrübeye sahip olmalısın. Matematiksel okuryazarlık da böyle bir sürü şeyi birlikte düşünmen, ilerisin düşünmen ve bu konuda tecrübeli olman gerekli."

Matematiksel okuryazarlığı parça-bütün ilişkisi olarak tanımlayan öğretmen adaylarının oluşturdukları metafor alt kategorileri Tablo $8^{\prime}$ de sunulmuştur.

Tablo 8. Parça-bütün ilişkisi olarak matematiksel okuryazarlık

\begin{tabular}{lll}
\hline Metafor & f & \% \\
\hline Yapboz & 32 & 2,15 \\
Aile & 4 & 0,26 \\
Piramit & 1 & 0,06 \\
Domino taşları & 6 & 0,40 \\
Zincir & 4 & 0,26 \\
Notalar & 1 & 0,06 \\
Motorun parçaları & 3 & 0,20 \\
\hline TOPLAM & $\mathbf{5 1}$ & $\mathbf{3 , 4 2}$ \\
\hline
\end{tabular}


Tablo 8 incelendiğinde, araştırmanın çalışma grubunda yer alan öğrencilerden 51' inin $(\% 3,42)$ matematiksel okuryazarlığa ilişkin metaforlarının, "Parça - Bütün İlişkisi” kategorisinde toplandığı görülmektedir.

Bunlardan "Yapboz" (\%2,15), "Domino Taşları" (\%0,40), “Aile” (\%0,26), "Zincir" $(\% 0,26)$ ve "Motorun Parçaları" $(\% 0,20)$ baskın metaforlar olarak değerlendirilmiştir (Tablo 8). Bu değerlendirmeyi destekleyici nitelikte bir aday öğretmenin görüşleri şu şekildedir:

"Matematiksel okuryazarlı yapbozlar gibidir çünkü yapbozda pek çok parça vardır. Insan bir parçayı eline aldığında oradaki küçük resimden, büyük resmi tahmin etmeye çalışır, parçanın nereye konulacağını da sonunda büyük resme ulaşılır. Burada biten şekle yapboz denilir. Yani parçalar aslında birleşince amaca uygun bir anlaml ifade eder, tek tek ise yine anlamlıdır fakat anlam verme şeklin özelliklerine olur. Matematiksel okuryazarlıkta da tek tek pek çok matematik bilgisinin anlamı mutlaka vardır. Ama bir araya getirme sonucu ortaya konulanın anlamı daha büyüktür. Birde bazı insanlar 100'lük bazılarl 5000'lik yapboz yapabilirler. Bu tecrübe ve yetenekle açılanabilir. Matematiksel okuryazarlıkta da bunlar gereklidir."

Matematiksel okuryazarlığ 1 bir el becerisi olarak tanımlayan öğretmen adaylarının oluşturdukları metafor alt kategorileri Tablo 9' da sunulmuştur.

Tablo 9. El becerisi olarak matematiksel okuryazarlık

\begin{tabular}{lll}
\hline Metafor & f & $\mathbf{\%}$ \\
\hline Elmas işleme & 3 & 0,20 \\
Örgü örmek & 2 & 0,13 \\
Resim yapma & 7 & 0,47 \\
Hattatlı & 6 & 0,40 \\
Ebru yapma & 1 & 0,06 \\
\hline TOPLAM & $\mathbf{1 9}$ & $\mathbf{1 , 2 7}$ \\
\hline
\end{tabular}

Tablo 9 incelendiğinde, araştırmanın çalışma grubunda yer alan öğrencilerden 19' unun $(\% 1,27)$ matematiksel okuryazarlığa ilişkin metaforlarının, "El Becerisi” kategorisinde toplandığı görülmektedir.

Bunlardan "Resim Yapma" (\%0,47), "Hattatlık" (\%0,40), "Elmas İşleme" $(\% 0,20)$ baskın metaforlar olarak değerlendirilmiştir (Tablo 9). Bu değerlendirmeyi destekleyici nitelikte bazı aday öğretmen ifadeleri şu şekildedir:

"Matematiksel okuryazarlık resim yapma gibidir çünkü, resim yapabilme bir yetenektir, matematiksel okuryazarlık ta bir yetenektir. Insan resim çizmeye yönelik bazı şeyleri ögrenebilir. Daha güzel resimler çizebilir. Ama bu ressam olduğu anlamina gelmez. Matematiksel okuryazarlıkta da durum böyle. Matematiği ögrenebilirsin ama bu, öğrendiklerini hayatta kullanabileceğin anlamına gelmez. Bazıları bu konuda daha yeteneklidir."

"Matematiksel okuryazarlık hattatlık gibidir çünkü nasıl bir hattat yazacă̆ metnin içeriğine, yazı biçimine, kâğıttaki görüntüsüne vs. karar verip yazıyorsa, matematiksel okuryazarlıkta da böyle bir çok şeye birlikte karar verilmelidir. Nasıl hattatın sanatkârlığı bunların hepsini yapabilmeyle ilgiliyse diğerinin başarılı olup olmadı̆̆ pek çok etmeni birlikte yapmaslyla alakalı." 
Matematiksel okuryazarlığı uyum ve düzen gerektiren yapılar olarak tanımlayan öğretmen adaylarının oluşturdukları metafor alt kategorileri Tablo 10' da sunulmuştur.

Tablo 10. Uyum ve düzen gerektiren yapılar olarak matematiksel okuryazarlık

\begin{tabular}{lll}
\hline Metafor & $\mathbf{f}$ & $\mathbf{\%}$ \\
\hline Deniz & 11 & 0,74 \\
Okyanus & 5 & 0,33 \\
Çöl & 4 & 0,26 \\
Uzay & 13 & 0,87 \\
Galaksi & 12 & 0,80 \\
Dünya & 45 & 3,02 \\
Ekosistem & 6 & 0,40 \\
Orman & 29 & 1,94 \\
Çiçek bahçesi & 4 & 0,26 \\
Arıkovanı & 2 & 0,13 \\
Karınca yuvası & 1 & 0,06 \\
\hline TOPLAM & $\mathbf{1 3 2}$ & $\mathbf{8 , 8 6}$ \\
\hline
\end{tabular}

Tablo 10 incelendiğinde, araştırmanın çalışma grubunda yer alan öğrencilerden 132 ' sinin $(\% 8,86)$ matematiksel okuryazarlığa ilişkin metaforlarının, "Uyum ve Düzen” kategorisinde toplandığı görülmektedir.

Bunlardan "Dünya" (\%3,02), "Orman" (\%1,94), "Uzay" $(\% 0,87)$, "Galaksi” $(\% 0,80)$ ve "Deniz" $(\% 0,74)$ baskın metaforlar olarak değerlendirilmiştir (Tablo 10). Bu değerlendirmeyi destekler nitelikteki bazı aday öğretmen görüşleri şu şekildedir:

"Matematiksel okuryazarlı dünya gibidir çünkü dünyada bütün canlı ve cansız varlıklar birlikte yaşarsa, birinin yaşaması için diğerinin varlığına ihtiyaç varsa, matematiksel okuryazar olabilmek için de hem matematiksel unsurların hem de düşünme ile ilgili olanların bir arada, birbirini destekler şekilde bulunması gerekir."

"Matematiksel okuryazarlık orman gibidir çünkü ormanda farklı türdeki ağaçlar, bir sürü canlı, diğer bitkiler yaşar. O ormandaki sistem yüzyıllardır yaşayan canlıların en iyi derecedeki uyumu sonucu oluşmuştur. Farkl bitkiler yaşayamamış ortadan kaybolmuş bazı hayvanlar beslenecekleri türde canlı olmadığı için orayı terk etmiş vb. Yani ideal uyumlu bir yapı yaşantılar sonucu oluşmuş. Matematiksel okuryazarlıkta da böyle pek çok bilgi, zaman içinde belli durumlara göre denenmiş bazılarının doğruluğu ve birlikte kullanılabilirliği doğrulanmış, bazıları ise o durum için gereksiz görülmüş. böylece bir alt yapı oluşturulmuş."

Matematiksel okuryazarlığı işlevsel bir araç olarak tanımlayan öğretmen adaylarının oluşturdukları metafor alt kategorileri Tablo 11' de sunulmuştur. 
Tablo 11. İşlevsel bir araç olarak matematiksel okuryazarlık

\begin{tabular}{lll}
\hline Metafor & f & \% \\
\hline Kap1 anahtar1 & 7 & 0,47 \\
Maymuncuk & 2 & 0,13 \\
Su anahtar1 & 1 & 0,06 \\
Vida & 1 & 0,06 \\
Gözlük & 4 & 0,26 \\
Süzgeç & 3 & 0,20 \\
\hline TOPLAM & $\mathbf{1 8}$ & $\mathbf{1 , 2 0}$ \\
\hline
\end{tabular}

Tablo 11 incelendiğinde, araştırmanın çalışma grubunda yer alan öğrencilerden 18 ' inin $(\% 1,20)$ matematiksel okuryazarlığa ilişkin metaforlarının, "İşlevsel Bir Araç" kategorisinde toplandığı görülmektedir.

Bunlardan "Kapı Anahtarı" (\%0,47), "Gözlük” (\%0,26), "Süzgeç" (\%0,20) baskın metaforlar olarak değerlendirilmiştir (Tablo 11). Bu değerlendirmeyi destekleyici nitelikte aday öğretmen ifadeleri şu şekildedir:

"Matematiksel okuryazarlık kapı anahtarı gibidir çünkü her kapının bir anahtarl vardır. Anahtara sahip olan o kaplyı kolaylıkla açar ve yoluna devam eder. Anahtarı olmayan uğraşır, belki açar belki açamaz. Böyle düşünürsek matematik okuryazarl olan kişi kapının anahtarl olan kişidir. Hayatı çözümleyebilir. Ve ilerler.

"Matematiksel okuryazarlık gözlük gibidir çünkü nasıl gözleri bozuk biri dünyayı tam olarak göremediği için anlamlandıramaz, Matematiği bilmeyen kişi de ayn şekilde dünyayı anlayamaz."

Matematiksel okuryazarlığı bir kurum olarak tanımlayan öğretmen adaylarının oluşturdukları metafor alt kategorileri Tablo 12' de sunulmuştur.

Tablo 12. Bir kurum olarak matematiksel okuryazarlık

\begin{tabular}{lll}
\hline Metafor & f & \% \\
\hline Banka & 1 & 0,06 \\
Postane & 1 & 0,06 \\
Lokanta & 1 & 0,06 \\
Okul & 1 & 0,06 \\
Hastane & 1 & 0,06 \\
\hline TOPLAM & $\mathbf{5}$ & $\mathbf{0 , 3 0}$ \\
\hline
\end{tabular}

Tablo 12 incelendiğinde, araştırmanın çalışma grubunda yer alan öğrencilerden 5' inin $(\% 0,30)$ matematiksel okuryazarlığa ilişkin metaforlarının, "Bir Kurum" kategorisinde toplandığı görülmektedir.

Bunlardan "Banka, Postane, Lokanta, Okul ve Hastane" $(\% 0,06)$ eşit oranlara sahip metaforlardır. Bu kategorileri destekleyici nitelikte bazı aday öğretmen görüşleri şu şekildedir:

"Matematiksel okuryazarlık lokanta gibidir çünkü lokantalarda öncelikle gıda maddeleri ham bir şekilde stoklanır, ardından müşterinin isteğine göre gereken maddeler bir araya getirilerek yemek yapllır ve servis yapllır. Mühim olan, yani iyi bir lokantanin özelliği uygun gıda maddesini mesela et, sebze, uygun oranlarda bir araya getirebilmesidir." 
"Hastane gibidir, hastanelerde her hasta çeşitli belirtilerle başvuru yapar, ardından ön inceleme sonucunda doğru polikliniğe sevk edilir. Ardından oradaki uzman doktorlar, hastanın durumuna göre bir tedavi planlar, her hastanın tedavisi aslında farklıdır."

Matematiksel okuryazarlığı bir kişi olarak tanımlayan öğretmen adaylarının oluşturdukları metafor alt kategorileri Tablo 13' de sunulmuştur.

Tablo 13. Bir kişi olarak matematiksel okuryazarlık

\begin{tabular}{lll}
\hline Metafor & f & \% \\
\hline Bilim adamı & 1 & 0,06 \\
Süper kahraman & 1 & 0,06 \\
Baba & 1 & 0,06 \\
Bakkal & 1 & 0,06 \\
Manav & 1 & 0,06 \\
Mimar & 1 & 0,06 \\
\hline TOPLAM & $\mathbf{6}$ & $\mathbf{0 , 3 6}$ \\
\hline
\end{tabular}

Tablo 13 incelendiğinde, araştırmanın çalışma grubunda yer alan öğrencilerden 6' sının $(\% 0,36)$ matematiksel okuryazarlığa ilişkin metaforlarının, "Bir Kişi”" kategorisinde toplandığı görülmektedir.

Bunlardan "Bilim Adamı, Süper Kahraman, Baba, Bakkal, Manav, Mimar" $(\% 0,06)$ eşit oranlara sahip metaforlardır (Tablo 13). Bu sınıflamayı destekleyici nitelikte bazı aday öğretmen görüşleri şu şekildedir:

"Matematiksel okuryazarlık baba gibidir çünkü, babalar evdeki problemleri çözer. Problemler sürekli yaşanır. Ailenin tüm üyeleri eve problem getirir ve bunu babalar çözer."

"Matematiksel okuryazarlı mimar gibidir. Mimarlar, sürekli farklı yerler için proje çizerler. Yani bildiklerini doğrudan aktarmazlar. Yeni karşılaştıkları duruma göre bunları bir araya getirirler."

\section{TARTIŞMA ve SONUÇ}

Araştırmanın bulgularına göre, öğretmen adayları matematiksel okuryazarlık kavramına ilişkin 94 geçerli metafor üretmişlerdir. Matematiksel okuryazarlık kavramına ilişkin çok fazla metafor üretilmiş olması bu kavramın geniş, kapsamlı, karışık ve soyut olduğunun göstergesi olarak değerlendirilebilir. $\mathrm{Bu}$ durum literatürü destekleyici niteliktedir (OECD, 2006; TIMMS, 2003; MCATA, 2000). Ayrıca metaforların seçmece olduğu ve tanımlamaya çalıştıkları olgunun sadece bir parçasını temsil ettiği düşünüldügüünde (Weade ve Ernst, 1990), matematiksel okuryazarlık gibi kompleks bir kavramın açıklanmasında çok sayıda metaforun ortaya çıkmasının normal bir sonuç olarak değerlendirilmesi mümkündür.

Sınıf öğretmeni adayları tarafindan üretilen 94 metafor toplam 11 kategori altında toplanmıştır. Bunlar sırasıyla; Günlük Hayat Faaliyeti (\% 29,75), Bir AraçAlet Kullanma Becerisi (\% 23,37), Mutfak Faaliyeti (\% 14,57), Zihinsel Beceri (\% 14,23), Uyum ve Düzen Gerektiren Yapılar (\%8,86), Parça-Bütün İlişkisi $(\% 3,42)$, Karmaşık Bir Yapı $(\% 2,55)$, El Becerisi $(\% 1,27)$, İşlevsel Bir Araç 
$(\% 1,2)$, Bir Kişi $(\% 0,36)$ ve Bir Kurum $(\% 0,30)$ şeklinde sıralanmaktadır. Literatürde kavrama ilişkin tanımlar incelendiğinde özellikle matematiksel okuryazarlık faaliyetlerinin günlük hayatla ilişkilendirilmesinin gerekliliğinin vurgulandığı görülmektedir (OECD, 2006; Aksu, Demir ve Sümer, 1998; MCATA, 2000, Özgen ve Bindak, 2011; Tekin ve Tekin, 2004). Ortaya konulan kategoriler içerisinde en fazla tekrarlanmış olduğu ifade edilenlerin (günlük hayat faaliyeti, bir araç-alet kullanma becerisi, mutfak faaliyeti) günlük hayatla ilişkili durumlar olması ögretmen adaylarının kavrama ilişkin algılarının matematiksel okuryazarlık için literatürde ortaya konulan kavramsal çerçeve ile uyumlu olarak değerlendirilebilir.

Ayrıca elde edilen veriler kategoriler göz önüne alınmadan, metafor bağlamında ele alınacak olursa, sınıf öğretmeni adayları tarafından ortaya konulan metaforlardan en fazla tekrar edilenler; Yemek Hazırlama (\% 14,57), Bilgisayar Kullanma (\% 8,60), Alışveriş Yapma (\% 8,6), Araba Kullanma (\% 6,78), Problem Çözme (\% 3,69), Dünya (\% 3,02), Telefon Kullanma (\% 2,75), Yapboz (\% 2,15), Orman (\% 1,94), Gelecek (\% 1,07), Uzay (\% 0,87) şeklinde sıralanmışı̧ır. Elde edilen metaforlardan 22 tanesi sadece bir katılımcı tarafindan ifade edilmiş̧ir (Mimar, Vida, Piramit). Yukarıda ifade edilen ve en fazla tekrar edildiği belirtilen metaforlar değerlendirildiğinde, bunların pek çoğunun üst düzey düşünme becerilerini (analiz, sentez, değerlendirme vb.) gerektirdiği görülmektedir. $\mathrm{Bu}$ değerlendirme de literatürle uyumlu olarak yorumlanabilir. Matematiksel okuryazarlık literatürde sıklıkla üst düzey düşünme becerileriyle tanımlanmaktadır (MCATA, 2000). 


\section{KAYNAKLAR}

Aksu, M., Demir, C., \& Sümer, Z. (1998). Matematik Öğretmenlerinin ve Öğrencilerinin Matematik Hakkındaki İnançları, III. Ulusal Fen Bilimleri Eğitimi Kongresi (s. 35-40). Trabzon: KTÜ.

EARGED, (2010). PISA 2009 Uluslararası Öğrenci Değerlendirme Programı Ulusal Ön Rapor, Ankara.

Finlay, L. (2008). A dance between the reduction and reflexivity: Explicating the "phenomenological psychological attitude". Journal of Phenomenological Psychology, 39(2008), 1-32.

Mathematics Council of the Alberta Teachers' Association [MCATA] (2000). Paper on Mathematical Literacy. 26. http://www.pacificlearning.com/ (erişim tarihi 20.05.2016).

MEB (2005). Matematik Dersi Öğretim Programı ve Klavuzu (1-5. Sınıflar), Ankara.

NCTM (2000). Principles and Standarts for School Mathematics. National Council of Teachers of Mathematics, Reston/VA.

OECD (2006).Assessing Scientific, Reading and Mathematical Literacy, A Framework for PISA 2006, http://www.pisa.oecd.org. (erişim tarihi: 20.05.2016).

Oxford, R. L.; Tomlinson, S.; Barcelos, A.; Harrington, C.; Lavine, R. Z.; Saleh, A. ve Longhini, A. (1998). Clashing metaphors about classroom teachers: Toward a systematic typology for the language teaching field. System, 26, 3-50

Özgen, K. ve Bindak, R. (2011). Lise Öğrencilerinin Matematik Okuryazarlığına Yönelik Öz-Yeterlik İnançlarının Belirlenmesi, Kuram ve Uygulamada Ĕgitim Bilimleri, 11(2), 1073-1089.

Saban, A. (2008). Okula ilişkin Metaforlar, Kuram ve Uygulamada Ĕgitim Yönetimi, Yaz 2008, Sayı 55, ss: 459-496

Tavşancıl, E. \& Aslan E. (2001). İçerik Analizi ve Uygulama Örnekleri. Epsilon Yayınları: İstanbul.

Tekin, B. ve Tekin, S., (2004). Matematik Öğretmen Adaylarının Matematiksel Okuryazarlık Düzeyleri Üzerine Bir Araştırma, http://www.matder.org.tr/Default.asp?id=85. (erişim tarihi: 20.05.2016).

TIMSS (2003). Trends in International Mathematics and Science Study. National Center for Education Statistics, http://www.nces.ed.gov/timss. (erişim tarihi: 20.05.2016).

Weade, R., \& Ernst, G. (1990). Pictures of life in classrooms, and the search for metaphors to frame them. Theory into Practice, 29(2), 133-140.

Yıldırım, A. \& Şimşek, H. (2005). Sosyal bilimlerde nitel araştırma yöntemleri. Ankara: Seçkin Yayınevi. 


\section{EXTENDED ABSTRACT}

\section{Introduction}

Programme for International Student Assessment (PISA) defines mathematical literacy as: Mathematical literacy is an individual's capacity to identify and understand the role that mathematics plays in the world, to make well-founded judgements and to use and engage with mathematics in ways that meet the needs of that individual's life as a constructive, concerned and reflective citizen (OECD, 2006).

According to MCATA (2000), mathematical literacy should include the abilities of; • Connecting mathematics to the real world - Using mathematics appropriately in a variety of contexts $\bullet$ Communicating using the richness of the language of mathematics - Synthesizing, analyzing, and evaluating the mathematical thinking of others Appreciating the utility and the elegance of mathematics - Understanding and being conscious of what has been learned mathematically.

The main purpose of this study was to explore prospective primary teachers' perceptions about the concept of "mathematical literacy" through the use of metaphors. For this purpose, the research question was desinged as: "What are the methaphors of prospective primary teachers related to concept of mathematical literacy".

\section{Method}

The study was executed by using the "phenomenology" pattern, which is defined to be the most effective patterns. It is one of the qualitative study patterns and aims to reveal and interpret the perspectives and individual perceptions about a specific phenomenon (Yıldırım \& Simsek, 2005). It is thought that the fact that phenomenology allows the researcher to put forth judgments, prejudices, and assumptions better compared to other qualitative study patterns, ensures that the prospective primary teachers' perspective on the concept of mathematical literacy (Finlay, 2008). The phenomen which is focused on in this study is the prospective primary teachers' perceptions on the concept in question, as it is mentioned above.

The participants for this study included a total of 1525 prospective primary teachers enrolled in the Department of Elementary Education at the Faculty of Education of different state universites of Turkey, during the 2015-2016 school year. The easy accessibility sampling method was used to determine the study group of the study.

To collect the study data, each participant was asked to complete the prompt "Mathematical literacy is like . . because ..." Data collection process was taken 30 minutes long. The students were instructed to write an original metaphor that best represented their perceptions of the concept of "mathematical literacy"

For analyzing the methaphors the process of Saban (2008) was used: In the coding and elimination stage, all the metaphorical images supplied by the participants were simply coded (such as "driving", "cooking", etc.). Also, papers in which a metaphorical image was not clearly articulated $(n=36)$ were eliminated. 
In the sample metaphor compilation stage, a sample expression for each metaphor was selected by going through 94 metaphorical images. In the sorting and categorization stage, each of the 94 metaphorical images was analyzed to characterize its elements: (1) the metaphor topic (i.e., daily activities), (2) the metaphor vehicle (e.g., the source domain of the metaphor to which the metaphor topic is compared), and (3) the ground (e.g., the nature of the relationship between the metaphor topic and the metaphor vehicle). As a result of this inductive analysis procedure, 11 major conceptual themes were identified. In establishing the inter-rater reliability rate, the 11 categories were asked to specialists and the sample of metaphors were enclosed to readers. In the last stage, SPSS program was used to calculate the descriptive statistics of the 11 conceptual themes

\section{Result and Discussion}

As a result of this project, students produced a total of 94 metaphors about the concept of "mathematical literacy." The metaphors were collected 11 categories by the researchers.

(1) 5 dominant metaphors conceiving "mathematical literacy" as "cooking", "shopping", "budgeting", "buying gift" and "getting on a bus". The metaphors were categorized as "daily activites." by the researchers. These metaphors were generated by a total of 443 students $(29,75 \%)$.

(2) 5 dominant metaphors conceiving "mathematical literacy" as "using computer", "driving a car", "using a smartphone", "using an ATM" and "flying". The metaphors were categorized as "the ability of instrument or vheicle." by the researchers. These metaphors were generated by a total of 348 students $(23,37 \%)$.

(3) 5 dominant metaphors conceiving "mathematical literacy" as "making cake", "making mixed vegetables", "making pizza", "making pastry" and "preparing breakfast". The metaphors were categorized as "kitchen activities." by the researchers. These metaphors were generated by a total of 217 students $(14,57 \%)$.

(4) 5 dominant metaphors conceiving "mathematical literacy" as "problem solving", "reasoning", "evaluation", "analyze" and "arithmetic". The metaphors were categorized as "mental activities." by the researchers. These metaphors were generated by a total of 212 students $(14,23 \%)$.

(5) 5 dominant metaphors conceiving "mathematical literacy" as "world", "space", "galaxy", "jungle" and "sea". The metaphors were categorized as "harmony and order." by the researchers. These metaphors were generated by a total of 132 students $(8,86 \%)$.

(6) 5 dominant metaphors conceiving "mathematical literacy" as "puzzle", "domino", "family", "chain" and "parts of motor". The metaphors were categorized as "partwhole relation." by the researchers. These metaphors were generated by a total of 51 students $(3,42 \%)$. 
(7) 4 dominant metaphors conceiving "mathematical literacy" as "future", "exams", "rubiks cube" and "maze". The metaphors were categorized as "complexity." by the researchers. These metaphors were generated by a total of 38 students $(2,55 \%)$.

The most frequently repeated metaphors by class teacher candidates were arranged as; preparing a meal, using a computer, doing shopping, driving a car, solving a problem, earth, using phone, jigsaw, forest, future and space. When the most frequently repeated metaphors were evaluated, it was seen that they required high level thinking skills (analyis, synthesis, evaluation). These results were evaluated parallel to the literature. 